\title{
Small intestinal transit, absorption, and permeability in patients with AIDS with and without diarrhoea
}

D Sharpstone, P Neild, R Crane, C Taylor, C Hodgson, R Sherwood, B Gazzard, I Bjarnason

\begin{abstract}
Background-Diarrhoea in AIDS is associated with anorexia and weight loss. The importance of gastrointestinal transit in such symptoms has not been addressed. Aims-To assess jejunal to caecal transit times in subjects with AIDS related diarrhoea and weight loss and correlate these with measures of absorptive capacity and intestinal permeability.

Methods-Jejunal to caecal transit times were assessed in 20 seronegative controls and 60 HIV seropositive subjects from serum analysis of 3-O-methyl-D-glucose and sulphapyridine after ingestion of the monosaccharide and sulphasalazine in aqueous solution. The method also allows an estimation of gastric emptying times for liquids. Intestinal absorptive capacity and permeability were assessed by a combined test using 3-O-methyl-D-glucose, D-xylose, L-rhamnose, and lactulose.
\end{abstract}

Results-Gastric emptying was significantly delayed in all groups of patients with AIDS. Mean jejunal to caecal transit times were not significantly different between controls (246 (62) minutes) and patients without diarrhoea (AIDS, well: 278 (103) minutes; AIDS, wasting: 236 (68) minutes), cytomegalovirus colitis (289 (83) minutes), pathogen negative diarrhoea (192 (100) minutes), or microsporidiosis (190 (113) minutes), although $30 \%$ of patients had values below the control range. Patients with cryptosporidiosis differed significantly from controls (135 (35) minutes, $p<0.0001$ ), seven of 10 having rapid transit times. Absorptive capacity was reduced and intestinal permeability significantly increased in AIDS, but did not correlate significantly with transit times.

Conclusion-Small bowel transit is accelerated in many patients with AIDS, particularily in protozoal diarrhoea, but is not the sole explanation for malabsorption of monosaccharides.

(Gut 1999;45:70-76)

Keywords: intestinal infection; intestinal absorption; intestinal transit; intestinal function; AIDS; HIV

Gastrointestinal symptoms are common and distressing features of HIV infection. Watery diarrhoea with increased stool frequency is a major cause of morbidity in AIDS and is often associated with profound weight loss. Diarrhoea is likely to be multifactorial, but the role of altered small bowel transit and its contribution to malabsorption has not been studied. The relevance of rapid intestinal transit in the pathogenesis of diarrhoea is suggested by the usually good response to opiate antidiarrhoeal agents. Furthermore, there is clearly a discrepancy between mild mucosal structural changes in the jejunum and ileum and the often severe malabsorption of simple sugars, vitamin $B_{12}$, and bile acids, ${ }^{12}$ which might be at least in part due to rapid intestinal transit.

Most non-invasive methods for assessing small intestinal transit measure orocaecal transit time, such as the hydrogen breath test following lactulose ingestion and serum sulphapyridine following sulphasalazine, but the results are affected by gastric emptying. In HIV seropositive individuals, symptoms suggestive of gastroparesis (early satiety) are common and may complicate the interpretation of orocaecal transit tests by underestimating the severity of rapid intestinal transit and its role in diarrhoea and malabsorption. In this study we used a technique which separates gastric emptying and jejunal to caecal transit using a liquid test solution in a large number of patients with AIDS, and correlated results with small bowel absorption and permeability.

\section{Materials and methods}

STUDY POPULATION

Between May 1992 and November 1995, 60 subjects (mean age 37 (SD 6) years) were recruited from the HIV/GUM departments and wards at the Chelsea and Westminster Hospital and King's College Hospital. Subjects were positive for HIV antibody by enzyme linked immunosorbent assay (ELISA) and line immunoassay (INNO-LIA for HIV-antibody 1 and 2, Inc star, Wokingham, UK) and all had a positive AIDS diagnosis, ${ }^{3}$ stage IV C1. The following patient groups with AIDS were examined: asymptomatic; wasting (involuntary loss of greater than $10 \%$ of body weight in the last year) with solid stool; pathogen negative diarrhoea (bowel movement three or more times a day with loose or liquid stools for longer than a month and no pathogens in at least three stool samples, small and large bowel biopsy); cytomegalovirus (CMV) colitis; and small bowel cryptosporidiosis or microsporidiosis. Exclusion criteria were: dual intestinal infection; upper gastrointestinal CMV; vomiting; renal impairment (serum creatinine more than $120 \mathrm{mmol} / \mathrm{l}$ );

Abbreviations used in this paper: $\mathrm{CMV}$, cytomegalovirus.
Gastroenterology, Guy's,

Medical Schools, Bessemer

Road, London SE5 9PJ, UK.

Accepted for publication 25 January 1999 
and significant neurological, pulmonary, cardiovascular, or hepatic disease, malignancy, or diabetes.

Thirty three per cent of patients were on zidovudine, zalcitabine, or didanosine. Fifty eight per cent were on cotrimoxazole, $28 \%$ on dapsone, $8 \%$ on inhaled or intravenous pentamidine, and 6\% took no Pneumocystis carinii prophylaxis. Previous studies have not shown any significant effect of these drugs on intestinal function (absorption, permeability, and inflammation). ${ }^{12}$ However, although none of the drugs that the HIV seropositive patients took has previously been shown to have a direct effect on neuromuscular transmission and none has been implicated in altering intestinal transit times, it was impractical to test the effect of individual drugs and the various drug combinations on intestinal transit.

Twenty healthy, presumed HIV seronegative, clinic staff and medical students, without gastrointestinal symptoms and not receiving any medication, were recruited as controls for the transit studies (mean age 33 (4) years). A normal reference range for the absorption permeability test was obtained from the same 20 volunteers and was similar to that previously established, ${ }^{2}$ based on 57 healthy volunteers.

All subjects gave written informed consent to these studies which were approved by the ethical committees of the Harrow, Camberwell, and Riverside Health Authorities.

STOOL ANALYSIS

All HIV seropositive subjects provided three stool samples within two weeks of study entry. Stool samples were cultured on standard media for pathogenic bacteria followed by full identification with standard biochemical tests. Smears were stained with auramine phenol for cryptosporidia and if positive, diagnosis was confirmed by a modified Ziehl-Neelsen stain. Specimens were inoculated onto Löwenstein-Jensen slants and cultured for mycobacteria. A standard formalin-ether concentration method was used to look for ova and parasites by direct microscopy. Concentrated preparations were examined for cryptosporidia if three standard preparations were negative. Three stools were examined for microsporidia spores using a calcoflur stain and Weber's strong trichrome method. ${ }^{4}$ A cytotoxicity assay for Clostridium difficile toxin was carried out on one stool sample from all the HIV seropositive patients. One stool specimen from each patient was also examined by electron microscopy for enteric viruses.

MUCOSAL BIOPSY

Oesophagogastroduodenoscopy with four distal duodenal biopsies and sigmoidoscopy or colonoscopy with biopsy were performed on all subjects with diarrhoea and/or weight loss. Impression smears were made from one duodenal biopsy, air dried, fixed for one to two minutes, stained with Giemsa, and examined under oil immersion $(\times 1000)$. All histological biopsy specimens were fixed in $10 \%$ formalin saline and paraffin wax sections $2-5 \mu \mathrm{m}$ thick were stained with haematoxylin and eosin, periodic acid Schiff (PAS), PAS-diastase, and
Ziehl-Neelsen stains; at least two levels per block were examined. Immunoperoxidase staining for CMV and adenovirus was performed on all rectal and duodenal biopsy specimens. The primary antibodies used were as follows: for CMV a mouse monoclonal antibody (Dakopatts, Denmark) in a dilution of $1 / 100$ and for adenovirus, mouse monoclonal antibody (Serotec, Oxford, UK) in a dilution of $1 / 1000$. The secondary antibody used was biotinylated horse antimouse monoclonal (Vector, Peterborough, UK) in a dilution of $1 / 300$ and the third layer was Avidin-Biotin (Vector) in a dilution of $1 / 100$.

TEST RATIONALE FOR MEASUREMENT OF JEJUNAL TO CAECAL TRANSIT TIME AND LIQUID GASTRIC EMPTYING TIME

The main objective of the transit test was to compare the time for appearance of two well characterised indicators absorbed from a defined region in the intestinal tract, allowing calculation of jejunal to caecal transit time. The indicators were 3-O-methyl-D-glucose and sulphasalazine which were administered in an aqueous solution. 3-O-methyl-D-glucose is absorbed rapidly (within minutes following direct instillation in normals) from the jejunum ${ }^{5}$ by an active carrier mediated transport system shared with D-glucose and D-galactose. ${ }^{6}$ The lag time from ingestion of the solution and first appearance of 3-O-methyl-D-glucose in serum should therefore indicate the arrival of the "head" of the test solution in the jejunum, providing an index of orojejunal transit which is principally determined by the gastric emptying time of a liquid test solution. Sulphasalazine, on the other hand, passes intact through the small bowel lumen in normals and is metabolised in the caecum by azo-reductase of bacteria to yield 5-aminosalicylic acid and sulphapyridine. ${ }^{7}$ Sulphapyridine is absorbed within minutes of caecal instillation ${ }^{8}$ and the use of serum sulphapyridine as a measure of orocaecal transit is well established..$^{59}$ Kellow and colleagues ${ }^{8}$ validated the sulphasalazine-sulphapyridine test by showing that sulphasalazine transit times from duodenum to caecum were comparable with simultaneously measured transit with technetium-99m labelled diethylenetriaminopentaacetate (scintigraphic study) and lactulose (breath test), as well as showing predictable transit time responses to poorly absorbed solute and morphine.

The reliability of "first appearance of markers in serum" to indicate arrival of test substances at a particular level in the intestine requires that mucosal uptake of the markers used is prompt and occurs at similar rates. In normal subjects, 3-O-methyl-D-glucose instilled into duodenum ${ }^{5}$ and sulphasalazine into the caecum, ${ }^{8}$ are associated with detectable serum concentrations of 3-O-methyl-D-glucose and sulphapyridine within 10 and six minutes, respectively. In the absence of significant large bowel disease in AIDS, permeation of sulphapyridine is assumed to be normal, as in inflammatory bowel disease.

However, two aspects of the transit time test required further validation. Firstly, we as- 
sessed the rate of appearance of 3-O-methyl$\mathrm{D}$-glucose in serum after intraduodenal instillation in patients with AIDS, as malabsorption of this sugar is common in these patients ${ }^{210}$ and it is possible that this malabsorption is associated with delayed absorption. Six patients (mean age 30 (8) years) with AIDS were studied. These had stage IV C1 disease and were admitted to the wards for study of indigestion and diarrhoea, and/or weight loss. All had malabsorption of 3-O-methyl-Dglucose with the combined absorption permeability test $(11.4 \%, 14.3 \%, 19.7 \% .20 .0 \%$, $24.4 \%$, and $27.2 \%$, respectively; normal, more than $30 \%$ ). At endoscopy a $50 \mathrm{ml}$ test solution containing 3-O-methyl-D-glucose (2.5 g) was instilled directly into the third part of the duodenum. Blood samples were taken before and at two minute intervals after the dose for 14 minutes.

Secondly, although previous studies have not consistently shown significant small bowel bacterial overgrowth in AIDS, ${ }^{11}{ }^{12}$ it may be a problem in a subset of patients with AIDS. The effect of small bowel bacterial overgrowth on the metabolism of sulphasalazine and the interpretation of the test result was therefore assessed. Six patients with Crohn's disease (mean age 34 (10) years) were studied to assess the effect of small bowel overgrowth on transit time measurement by our transit time technique. All had small intestinal strictures and a positive ${ }^{14} \mathrm{C}$-glyocholate breath test for small bowel bacterial overgrowth, confirmed by coliform cultures from duodenal aspirates.

PROTOCOL FOR MEASUREMENT OF SMALL BOWEL TRANSIT AND GASTRIC EMPTYING

Subjects stopped all medication known to affect gastric emptying or small bowel transit such as opiate antidiarrhoeals, antiemetics, alcohol, and antibiotics (other than Pneumocystis carinii pneumonia prophylaxis) 48 hours before the transit test. Subjects fasted from midnight and an intravenous cannula was inserted into a large arm vein before the start of the test at $8 \mathrm{am}$. A baseline blood sample $(7 \mathrm{ml})$ was drawn and subjects ingested the $100 \mathrm{ml}$ test solution containing 3-O-methyl-D-glucose (5.0 g, Sigma Pharmaceuticals, Poole, UK) and sulphasalazine (3.0 g, sulphasalazine syrup, Kabi-Pharmacia, Milton Keynes, UK). Blood (7 ml) was drawn at 15, 30, 45, 60, 90, $120,150,180,240,300$, and 360 minutes. All subjects lay supine (except for use of the lavatory) and fasted throughout the test. Subjects had an intravenous infusion of 1 litre of normal saline in the opposite arm or via an indwelling venous catheter during the test.

SMALL BOWEL ABSORPTION/PERMEABILITY

Between two and five days after the small bowel transit test, subjects had a combined absorption and permeability test. Forty eight hours before the test, subjects abstained from taking any agents known to affect small bowel permeability, absorption, or motility, including nonsteroidal anti-inflammatory drugs, alcohol, antidiarrhoeals, and antibiotics. After an overnight fast subjects drank a $100 \mathrm{ml}$ test solution
(240 mosm/l) containing 3-O-methyl-Dglucose $(0.2 \mathrm{~g})$, D-xylose $(0.5 \mathrm{~g})$, L-rhamnose $(1.0 \mathrm{~g})$, and lactulose $(5.0 \mathrm{~g}=7.5 \mathrm{ml}$ of $67 \%$ wt/vol lactulose solution BP). A complete five hour urine collection was made into a bottle containing $1-2 \mathrm{ml}(10 \% \mathrm{wt} / \mathrm{vol})$ merthiolate as preservative. Baseline urine samples contained none of the test substances.

\section{MARKER ANALYSIS}

Serum 3-O-methyl-D-glucose was measured by thin layer chromatography and densitometry, ${ }^{13}$ and sulphapyridine by high pressure liquid chromatography with ultraviolet detection, ${ }^{14}$ with coefficients of variation characteristically $3.5-8.5 \%$ and $4-11 \%$, respectively. Urinary 3-O-methyl-D-glucose, D-xylose, L-rhamnose, and lactulose were measured by a quantitative thin layer chromatography method, ${ }^{13}$ modified to estimate both monosaccharides and disaccharides. ${ }^{15}$ The differential five hour urinary excretion ratio of lactulose and L-rhamnose (percentage ingested dose) provides an index of small bowel permeability. ${ }^{16}$

\section{STATISTICS}

Statistical analysis was performed using Analyse-It medical statistics addition to Microsoft Excel. A Shapiro-Wilks W prime test showed the absorption-permeability and transit data to be normally distributed while the gastric emptying data were not. Values for the former are therefore presented as mean (SD) and the latter as median and range. A one way analysis of variance (ANOVA) was used to show significant differences between the groups where the data were normally distributed; Student's $t$ test was then used to assess statistical differences between controls and the subgroups of HIV seropositive patients using Bonferroni's correction. The Mann-Whitney test was used to assess statistical differences in the gastric emptying data from controls and patients. Pearson's correlation coefficient was used to assess the correlation between measures of small bowel function.

\section{Results}

VALIDATION EXPERIMENTS

After intraduodenal instillation of 3-O-methylD-glucose in the six patients with AIDS and malabsorption of this monosaccharide, 3-Omethyl-D-glucose was detected in serum within six minutes (three at 2 minutes, two at 4 , and one at 6 minutes) which is comparable with that reported in normals. ${ }^{5}$ Figure 1 shows representative permeation profiles from controls and patients with AIDS and Crohn's disease.

In controls 3-O-methyl-D-glucose appeared in serum and rose sharply, usually within 15 minutes of ingestion of the transit time test solution. There was no measurable sulphapyridine until 180-360 minutes. When sulphapyridine appeared in the normal subjects it rose more than 10 -fold to $0.1-2 \%$ dose $/ 1$. One patient with AIDS is normal, the other showing delayed gastric emptying and rapid small intestinal transit. The patients with Crohn's strictures and bacterial overgrowth had the same sharp 3-O-methyl-D-glucose peak as controls. 
However, in five of the six patients low concentrations of sulphapyridine $(0.014-0.035 \%$ dose/l) were detected in serum until a more definite, and easily distinguishable, more than fivefold increase, resembling that seen in controls occurred. Figure 1 shows representative permeation profiles from two of these patients. Low concentrations of sulphapyridine were evident in serum prior to the characteristic and obvious increase which we take to indi-
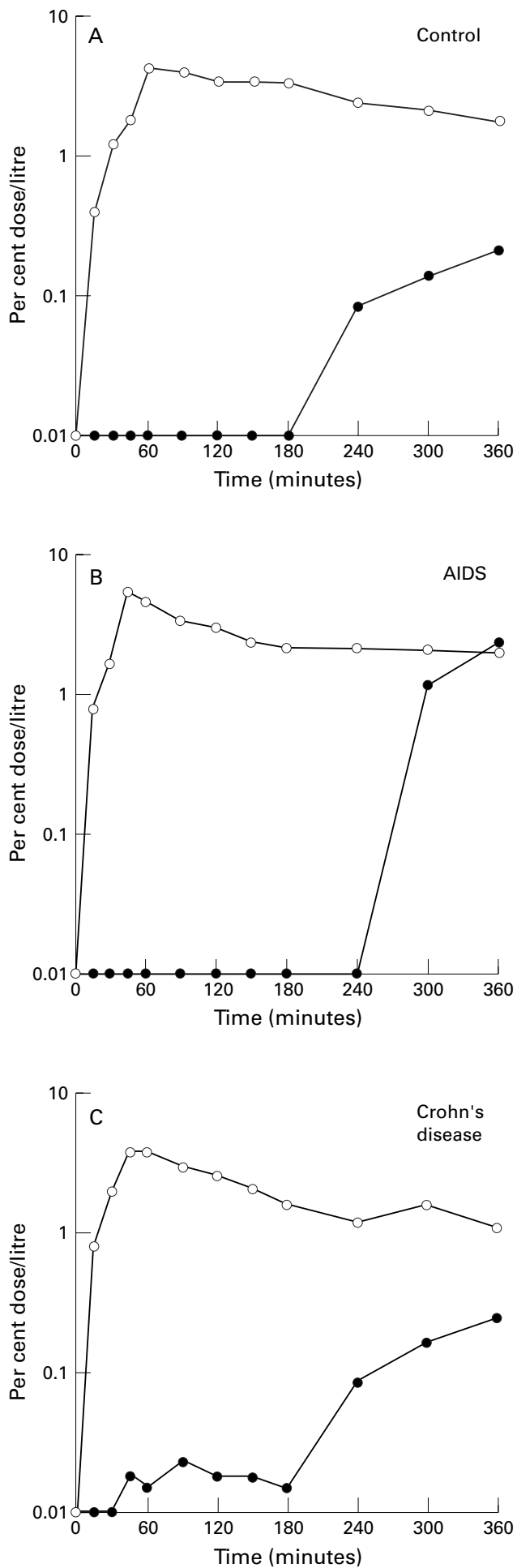

cate small intestinal bacterial metabolism of sulphasalazine and the arrival of the "head of the solution" in the caecum, respectively.

\section{GASTRIC EMPTYING}

Table 1 shows that gastric emptying of the liquid solution was significantly delayed in all subgroups of patients with AIDS compared with controls.
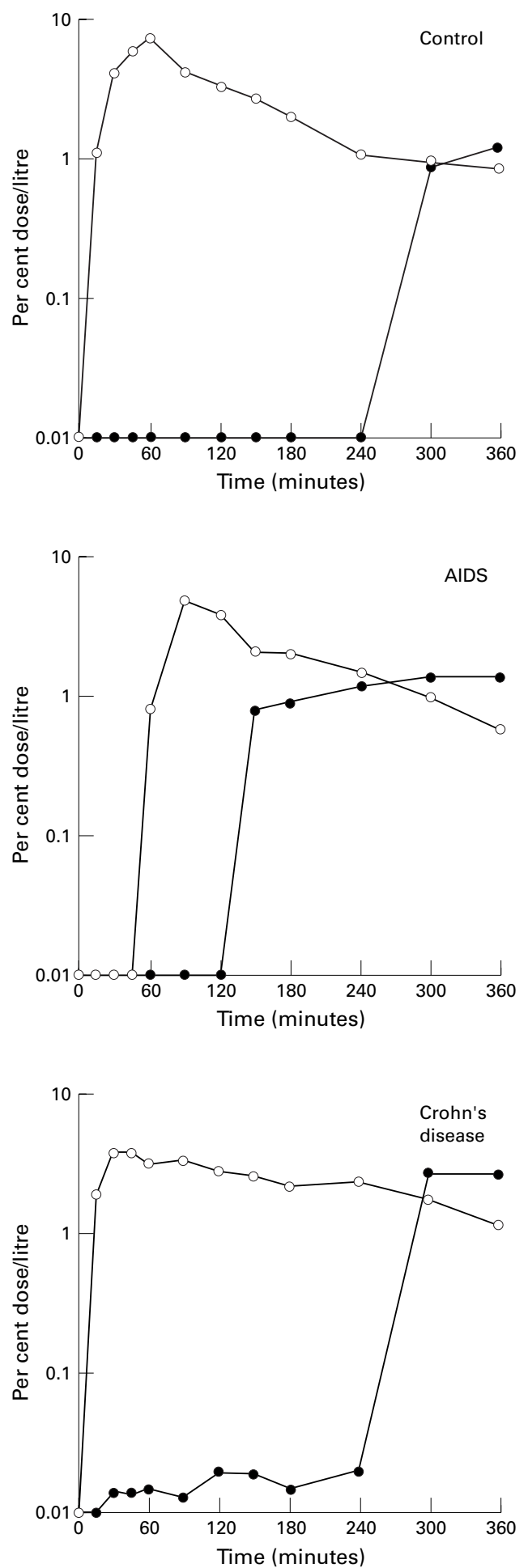

Figure 1 Representative permeation profiles of 3-O-methyl-D-glucose (open circles) and sulphapyridine (closed circles) after ingestion of the monosaccharide and sulphasalazine in two control subjects $(A)$, two patients with AIDS (B), and two patients with Crohn's disease associated with small bowel bacterial overgrowth $(C)$. 
Table 1 Gastric emptying of a liquid in AIDS

\begin{tabular}{ll}
\hline & $\begin{array}{l}\text { Median time (range) in } \\
\text { minutes of first appearance of } \\
\text { 3-O-methyl-D-glucose in serum }\end{array}$ \\
\hline Controls & $15(15-30)$ \\
AIDS, well & $22.5(15-60)^{\star}$ \\
AIDS, weight loss & $30(15-60) \dagger$ \\
Pathogen negative diarrhoea & $30(15-45) \ddagger$ \\
CMV colitis & $30(15-90)^{\star}$ \\
Microsporidiosis & $15(15-45)^{\star}$ \\
Cryptosporidiosis & $15(15-90)^{\star}$
\end{tabular}

Statistical analysis performed by the Mann-Whitney test. ${ }^{\star}$ Differed significantly from controls $(p<0.05)$.

+ Differed significantly from controls $(p<0.005)$.

$\neq$ Differed significantly from controls $(p<0.001)$.

$\mathrm{CMV}$, cytomegalovirus.

JEJUNAL TO CAECAL TRANSIT TIME IN AIDS

Table 2 shows that the 20 control subjects for the transit studies weighed significantly more

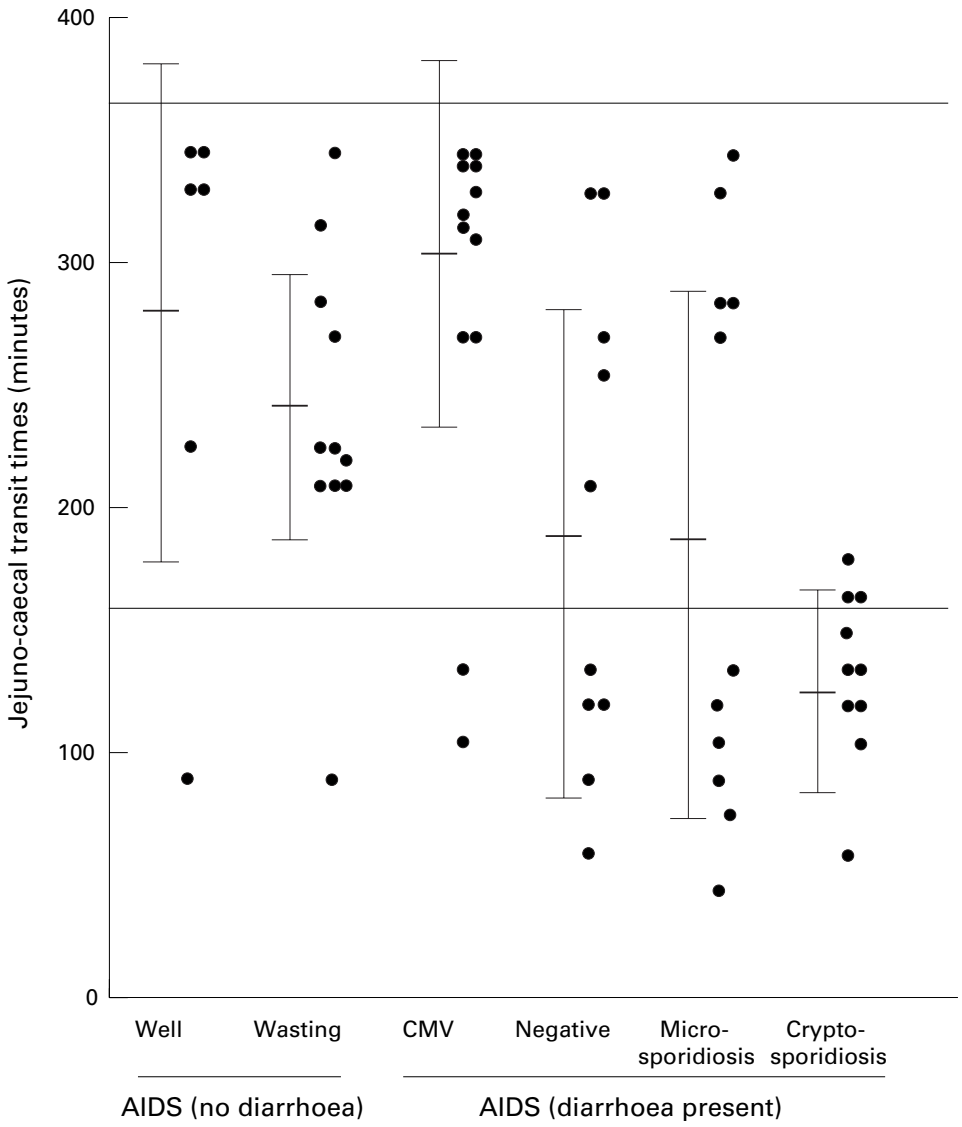

Figure 2 Individual jejunal to caecal transit times in the patients with AIDS. The two horizontal lines represent the upper and lower normal range as obtained from the 20 control subjects. Horizontal bars represent mean values and the vertical bars represent SD.

Table 2 Small intestinal absorption and permeability in AIDS than patients with AIDS, but there was no significant difference in weight between patients in the various subgroups with AIDS. Similarly CD4 count did not differ significantly between the AIDS subgroups.

Figure 1 shows representative permeation profiles from two patients with AIDS. The pattern, in comparison with controls, was often that of a variable delay of the appearance of 3-O-methyl-D-glucose. However, similar to controls, and unlike the pattern found in the Crohn's disease patients with small bowel bacterial overgrowth, there was a period where sulphapyridine was not measurable in serum. When sulphapyridine appeared it rose over fivefold to a plateau as in controls. Figure 2 shows the individual jejunal to caecal transit time (time of appearance of sulphapyridine less the time of appearance of 3-O-methyl-Dglucose) in controls (246 (SD 62) minutes); AIDS, well (278 (103) minutes); AIDS, wasting (236 (68) minutes); CMV colitis (289 (83) minutes); pathogen negative diarrhoea (192 (100) minutes); microsporidiosis (190 (113) minutes); and cryptosporidiosis (135 (35) minutes). A one way ANOVA showed significant $(p<0.0005)$ differences between the groups. Twenty two patients with AIDS (37\%) had evidence of rapid intestinal transit, but only in the group with cryptosporidiosis was the mean jejunal to caecal transit time significantly more rapid than in controls $(\mathrm{p}<0.0001$; Student's $t$ test with Bonferroni's correction). In the case of pathogen negative $(\mathrm{p}=0.07$; mean compared with normal) and microsporidial diarrhoea $(\mathrm{p}=0.08)$ half of the patients had evidence of a rapid jejunal to caecal transit.

\section{SMALL INTESTINAL ABSORPTION AND}

PERMEABILITY

Table 2 shows the results of the combined absorption-permeability test. The absorption of 3-O-methyl-D-glucose did not differ significantly from normal in patients with AIDS. There was significant malabsorption of the two other monosaccharides in all groups of patients with AIDS. Intestinal permeability was significantly increased in all subgroups except in AIDS, well patients.

There was no significant $(p>0.08)$ correlation between the urinary excretion of 3-Omethyl-D-glucose $(r=0.10)$, D-xylose $(r=0.12)$, and L-rhamnose $(r=0.24)$, or the differential

\begin{tabular}{|c|c|c|c|c|c|c|c|}
\hline & Number & $\begin{array}{l}\text { CD4 count } \\
\left(\text { cells } \times 10^{6} / l\right)\end{array}$ & $\begin{array}{l}\text { Body mass index } \\
\left.\text { (weight/ height }^{2}\right)\end{array}$ & $\begin{array}{l}\text { 3-O-m-D-glucose } \\
(\% \text { dose) }\end{array}$ & $D$-xylose (\% dose) & $\begin{array}{l}\text { L-rhamnose } \\
(\% \text { dose })\end{array}$ & $\begin{array}{l}\text { Lactulose/ } \\
\text { L-rhamnose }\end{array}$ \\
\hline Controls & 20 & & $26(2)$ & $47.5(11.1)$ & $31.7(7.3)$ & $12.8(2.6)$ & $0.03(0.01)$ \\
\hline AIDS, well & 6 & $112(146)$ & $21(3)^{\star}$ & $33.4(3.0)$ & $23.3(3.0) \ddagger$ & $5.0(1.4) \ddagger$ & $0.04(0.05)$ \\
\hline AIDS, weight loss & 11 & $9(9)$ & $18(2) \ddagger$ & $31.5(17.2)$ & $12.5(4.2) \ddagger$ & $3.4(1.3) \ddagger$ & $0.14(0.12) \ddagger$ \\
\hline Pathogen negative diarrhoea & 10 & $25(29)$ & $19(3) \dagger$ & $36.3(14.6)$ & $20.5(12.1) \ddagger$ & $4.7(2.3) \ddagger$ & $0.15(0.09) \ddagger$ \\
\hline CMV colitis & 12 & $35(41)$ & $20(4) \ddagger$ & $39.6(14.3)$ & $15.5(6.3) \ddagger$ & $4.2(1.5) \ddagger$ & $0.20(0.14) \ddagger$ \\
\hline Microsporidiosis & 11 & $37(52)$ & $19(3) \ddagger$ & $31.7(16.7)$ & $13.4(7.1) \ddagger$ & $3.2(2.1) \ddagger$ & $0.09(0.06) \ddagger$ \\
\hline Cryptosporidiosis & 10 & $19(15)$ & $18(4)^{\star}$ & $33.4(12.4)$ & $15.9(7.0) \ddagger$ & $3.7(1.7) \ddagger$ & $0.15(0.14) \ddagger$ \\
\hline
\end{tabular}

Values presented are mean (SD).

A one way ANOVA was showed significant $(\mathrm{p}<0.0001)$ differences in absorption-permeability data between the groups, apart from the 3-O-methyl-D-glucose group. ^Differed significantly from controls ( $\mathrm{p}<0.05$; Student's $t$ test using Bonferroni's correction).

+ Differed significantly from controls $(\mathrm{p}<0.01)$.

$\ddagger$ Differed significantly from controls $(\mathrm{p}<0.001)$.

CMV, cytomegalovirus. 
urinary excretion of lactulose/L-rhamnose $(r=-0.13)$ and jejunal to caecal transit times.

\section{Discussion}

This study shows a uniformly severe impairment of small bowel absorption and permeability in patients with AIDS. These changes are frequently associated with delayed gastric emptying of the liquid test solution and rapid intestinal transit, particularly in patients with pathogen negative and protozoal diarrhoea. There is no significant correlation between intestinal absorption/permeability parameters and transit times which may relate to the multifactorial nature of diarrhoea in these patients.

The definition of pathogen negative diarrhoea, in this and other studies, is a particularly contentious issue and it is possible that a more extensive investigation would have identified more pathogens in this group of patients. For instance, exclusion of the diarrhoea due to Clostridium difficile infection with one faecal sample can be improved somewhat by multiple sampling, ${ }^{17} 18$ and other techniques besides electron microscopy might be needed to exclude enteric viruses completely..$^{19}$ However, at the time of study a similar algorithm for investigation of diarrhoea associated with HIV was used by us in related studies of intestinal function in HIV/AIDS. ${ }^{12}$ The diagnostic label of "pathogen negative" diarrhoea needs to be viewed with this in mind as well as the fact that the diagnostic criteria for "pathogen negative" diarrhoea are constantly changing and difficult to anticipate prospectively.

\section{GASTRIC EMPTYING}

The primary aim of this study was to measure and correlate jejunal to caecal transit time with intestinal absorption and permeability. The choice of the transit test used was in part to control for possible delayed gastric emptying. The appearance of 3-O-methyl-D-glucose in serum provided a measure of gastric emptying of a liquid meal and was significantly delayed in all AIDS subgroups. Delayed gastric emptying may be the consequence of malnutrition, ${ }^{20}$ neuropathy ${ }^{21}$ or systemic disease ${ }^{22}$ and may explain symptoms such as early satiety, nausea, and bloating. Extrapolation of the results of a liquid test solution to what may happen with solid foods is, however, fraught with difficulty. Nevertheless, this study offers a logical rationale for studying gastric emptying of solid test meals in patients with HIV.

SMALL BOWEL TRANSIT

Our study indicates that rapid intestinal transit may contribute to diarrhoea in over $50 \%$ of patients with AIDS and cryptosporidiosis, microsporidiosis, and pathogen negative diarrhoea. A potential problem with the technique used for assessing the intestinal transit times, in common with most other non-imaging tests such as the lactulose breath test, is that significant small bowel bacterial overgrowth could lead to luminal metabolism of the test substance, giving an early signal mistakenly indicating that the "head" of the test solution had entered the caecum. To assess this we examined patients with Crohn's disease and small intestinal bacterial overgrowth. In these patients sulphapyridine was indeed detected in serum shortly after ingestion of the test solution. However, these low concentrations were easily distinguished from the definite and much higher rise in serum concentrations seen subsequently and resembling those in controls. These low concentrations, which we interpret as cleavage of the azo bond of sulphasalazine by the overgrowth of small intestinal bacteria, were not seen in any control subjects or patients with AIDS. While this argues against significant small bacterial overgrowth in the patients with AIDS, in keeping with some other studies, ${ }^{11}{ }^{12}$ this is not excluded as only azo-reductase containing bacteria split the azo bond of sulphasalazine.

The reason for rapid intestinal transit in half of the patients with AIDS with pathogen negative or protozoal diarrhoea is uncertain. Histopathological studies show damage to the intrinsic nerve plexus in jejunal and rectal biopsy specimens from patients with AIDS. ${ }^{23}{ }^{24}$ It is unclear whether enteric nerve damage precedes or is the result of protozoal infection, though generalised autonomic neuropathy is well described, particularly in late HIV infection, ${ }^{25}$ presumably as a direct consequence of the neurotropic effects of the virus. ${ }^{26}$ In either case, the often excellent symptomatic response to opiate antidiarrhoeals is consistent with the suggestion that intrinsic nerve plexus damage contributes significantly to rapid small bowel transit and diarrhoea in AIDS.

It has been suggested that microsporidiosis and cryptosporidiosis have different and distinct disease expression in HIV seropositive individuals. Microsporidiosis is characterised by increased faecal tumour necrosis factor $\alpha{ }^{27}$ a cachetic pattern of weight loss, ${ }^{28}$ and diarrhoea that may respond to the antitumour necrosis factor $\alpha$ agent, thalidomide. ${ }^{29}$ However, subjects with cryptosporidiosis have a decreased metabolic rate, ${ }^{28}$ characteristic of starvation, ${ }^{30}$ and normal tumour necrosis factor $\alpha$ in stools. ${ }^{27}$ Rapid small bowel transit in some of these patients could explain the starvation response, perhaps due to a voluntary reduction in food intake in order to decrease stool volumes.

Half of the patients with pathogen negative diarrhoea had rapid intestinal transit, which is further evidence for underlying pathology such as occult pathogens, an "HIV enteropathy", or neuronal damage.

SMALL INTESTINAL ABSORPTION AND PERMEABILITY

Enterocyte damage, perhaps secondary to $\mathrm{T}$ cell activation and release of cytokines, ${ }^{31}$ may lead to malabsorption of monosaccharides and increased small intestinal permeability. While malabsorption may contribute to weight loss and malnutrition, ${ }^{32}$ increased intestinal permeability may lead to an inflammatory enteropathy. ${ }^{1633} 34$ The prevalence and severity of malabsorption and increased intestinal permeability in this study is comparable with that found in previous work, ${ }^{12} 1035$ but lack of a 
significant correlation with transit time suggests a more complex pathogenesis for the diarrhoea.

The pathogenesis of gastrointestinal abnormalities in AIDS is complex and multifactorial and therefore unlikely to be explained by a single pathophysiological event. This study confirms that all groups of patients with AIDS have significant malabsorption and increased intestinal permeability. Accelerated small intestinal transit is a feature of many patients with pathogen negative and protozoal diarrhoea and may exacerbate anorexia and weight loss. Although the reasons for the motility alterations are unknown, the combination of a delay of gastric emptying of the liquid test solution and intestinal hurry might suggest an intestinal autonomic neuropathy.

This work was partially supported by a MRC project grant. C Hodgson was supported by an NHS Executive R\&D Grant.

1 Bjarnason I, Sharpstone D, Francis $\mathrm{N}$, et al. Intestinal inflammation, ileal structure and function in HIV. AIDS 1996;10:1385-91.

2 Keating J, Bjarnason I, Somasundaram S, et al. Intestinal absorptive capacity, intestinal permeability and jejunal histology in HIV and their relation to diarrhoea. Gut 1995;37: 623-9.

3 Anonymous. 1993 revised classification system for HIV infection and expanded surveillance case. Morbidity and Mortality Weekly 1993;41:1-18.

4 Weber R, Bryan RT, Owen RL, et al. Improved lightmicroscopical detection of microsporidia spores in stoo and duodenal aspirates. N Engl f Med 1992;326:161-6.

5 Teahon K, Somasundaram S, Smith T, et al. Assessing the site of increased intestinal permeability in coeliac and inflammatory bowel disease. Gut 1996;38:864-9.

6 Fordtran JS, Clodi PH, Soergel KH, et al. Sugar absorption tests, with special reference to 3-O-methyl-D-glucose and tests, with special reference to 3-O-methy

7 Peppercorn MA, Goldman P. The role of intestinal bacteria in the metabolism of salicylazosulfapyridine. I Pharmaco Exp Ther 1972;181:555-62.

8 Kellow JE, Borody TJ, Phillips SF, et al. Sulphapyridine appearance in plasma after salicylazosulfapyridine. Gastroenterology 1986;91:396-400.

9 Kennedy M, Chinwah P, Wade DN. A pharmacological method of measuring mouth caecal transit time in man. $B$ f Clin Pharmacol 1979;8:372-3.

10 Lim SG, Menzies IS, Lee CA, et al. Intestinal permeability and function in patients infected with human immunodeficiency virus. Scand 7 Gastroenterol 1993;28:573-80.

11 Budhraja M, Levendoglu H, Kocka F, et al. Dudenal mucosal $\mathrm{T}$ cell subpopulation and bacterial cultures in acquired immunodeficiency syndrome. Am $\mathcal{f}$ Gastroenterol 1987;82:427-31.

12 Neild P, Hannan M, Azadian B, et al. Basal gastric $\mathrm{pH}$ and duodenal bacterial colonisation in human immunodeficiency virus positive patients with and without
diarrhoea [abstract]. Gastroenterology 1996;110(suppl): A441.

13 Menzies IS, Mount JN, Wheeler MJ. Quantitative estimation of clinically important monosaccharides in plasma by rapid thin layer chromatography. Ann Clin Biochem $1978 ; 15: 65-76$

14 Chungi VS, Gurvinder SR, Shagrel L. A simple rapid liquid chromatographic method for the determination of major metabolites of sulphasalazine in biologic fluids. F Pharm Sci 1989;78:235-8.

15 Noone C, Menzies IS, Banatvala JE, et al. Intestinal permeability and lactulose hydrolysis in human rotaviral gastroenteritis assessed simultaneously by non-invasive differential sugar permeation. Eur f Clin Invest 1986;16:217-25.

16 Bjarnason I, Macpherson A, Hollander D. Intestinal perm

17 Katz DA, Lynch ME, Littenberg B. Clinical prediction rules to optimize cytotoxin testing for Clostridium difficile in to optimize cytotoxin testing for Clostridium difficile in 487-95.

18 Gerding DN. Diagnosis of Clostridium difficile-associated disease: patient selection and test perfection. $A m \mathcal{F} \mathrm{Med}$ 1996;100:485-6

19 Grohmann GS, Glass RI, Pereira HG, et al. Enteric viruses and diarrhoea in HIV-infected patients. $N$ Engl $f \mathrm{Med}$ 1993;329:14-20.

20 Rigaud D, Beding G, Merrouche M, et al. Delayed gastric emptying in anorexia nervosa is improved by completion of renutrition program. Dig Dis Sci 1998;33:919-25.

21 Hongo M, Okuno Y. Diabetic gastropathy in patients with autonomic neuropathy. Diabet Med 1993;10(suppl 2):79auton.

22 Bortoletti M, Bersani G, Labo G. Association between chronic idiopathic gastroparesis and cytomegalovirus infection. Gastroenterology 1987;92:1324.

23 Blanshard C, Ellis DS, Tovey G, Gazzard BG. Electron microscopy of rectal biopsies in HIV-positive individuals. $\mathcal{f}$ Pathol 1993;169:79-87.

24 Batman PA, Miller ARO, Sedgwick PM, et al. Autonomic denervation in jejunal mucosa of homosexual men infected with HIV. AIDS 1991;5:1247-52.

25 Rutimann S, Hilti P, Spinas GA, et al. High frequency of human immunodeficiency virus-associated autonomic neuropathy and more severe involvement in advanced stages of human immunodeficiency virus disease. Arch Intern Med 1991;151:2441-3.

26 Dawson TM, Dawson VL. Gp 120 neurotoxicity in primary cortical cultures. Adv Neuroimmunol 1994;4:167-73.

27 Sharpstone D, Rowbottom A, Lepper M, et al. Faecal tumour necrosis factor-alpha in HIV-related diarrhoea. AIDS 1996;10:989-94

28 Sharpstone D, Ross H, Gazzard BG. The metabolic response to opportunistic infections in AIDS. AIDS 1996; 10:1529-33.

29 Sharpstone D, Rowbottom A, Nelson M, et al. Thalidomide for microsporidiosis. AIDS 1995;9:658-9.

30 Macallan D, Noble C, Baldwin C, et al. Energy expenditure and wasting in human immunodeficiency virus infection. $N$ Engl f Med 1995;333:83-8.

31 Kotler DP, Reka S, Clayton F. Intestinal mucosal inflammation associated with human immunodeficiency virus infection. Dig Dis Sci 1993;38:1119-27.

32 Keusch GT, Thea DM. Malnutrition in HIV. Med Clin North Am 1993;77:795-814.

33 Bjarnason I, Macpherson A, Somasundaram S, et al. Nonsteroidal anti-inflammatory drugs and inflammatory bowel disease. Can 7 Gastroenterol 1993; 7:160-9.

34 Bjarnason I, Macpherson AJS, Somasundaram S, et al. Non-steroidal anti-inflammatory drugs and Crohn's disease. In: Scholmeric J, Kruis W, Goebbell $\mathrm{H}$, et al, eds. Inflammatory bowel diseases: pathophysiology as basis of treatInflammatory bowel diseases: pathophysiology as basis of treatment. Falk Symposium Publishers, 1993:208-22.

35 Ott M, Lembcke B, Staszewski S, Helm EB, et al. Intestinal permeability in patients with acquired immunodeficiency syndrome (AIDS). Klin Wochenschr 1991;69:715-21. 